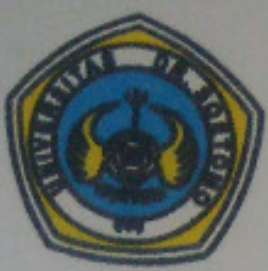

ISSN: $0854-4883$

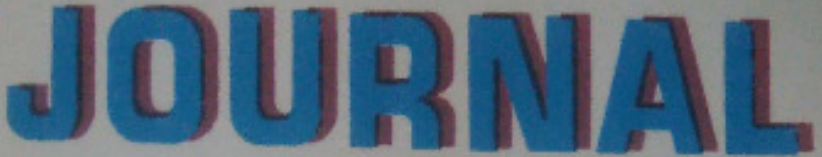

MAJALAH ILMIAH EKONOMI \& BISNIS

FAKULTAS BKONOMI - UNIVERSITAS Dn SOETOMO

PENGARUH PROGRAM KESELAMATAN KERJA

TERHADAP PRESTASI KERJA KARYAWAN

PT. SIANTAR TOP SURABAYA

Liosten Rianna Ully $T$

PENGARUH BRAND EQUITY TERHADAP COSTUMER VALUE PADA PENGGUNA TELEPON SELULER NOKIA

DI SURABAYA

Firdaus

EFEKTIFITAS PROGRAM ALOKASI DANA DESA (ADD)

TERHADAP PEREKONOMIAN DESA

DI KABUPATEN PACITAN

$29 x+2$

273 CARUH VARIABEL VARIABEL IKLAN TERHADAP MINAT 70 9 SUMEN UNTUK MEMBELI MOTOR HONDA SUPRA X 125 DI KAWASAN SURABAYA TIMUR

Mohammad Rusman

ANALISIS FAKTOR FAKTOR PROMOSI DALAM USAHA UNTUK MENINGKATKAN VOLUME PENJUALAN

Veronika Nugraheni Sri Lestari

STUDI PERBANDINGAN LAJU INFLASI TUJUH NEGARA INDUSTRI MAJU SEBELUM DENGAN SESUDAH KENAIKAN HARGA MINYAK

Wiwik Budiarti

ANALISIS PENGARUH KUALITAS PELAYANAN TERHADAP KEPUASAN ANGGOTA DI KOPERASI PEGAWAI REPUBLIK INDONESIA (KP-RI) BANGKIT KECAMATAN TRAGAH BANGKALAN

Manah Tarman

\begin{tabular}{|l|l|l|l|}
\hline Volume X & No.1 & Desember & 2007 \\
\hline
\end{tabular}




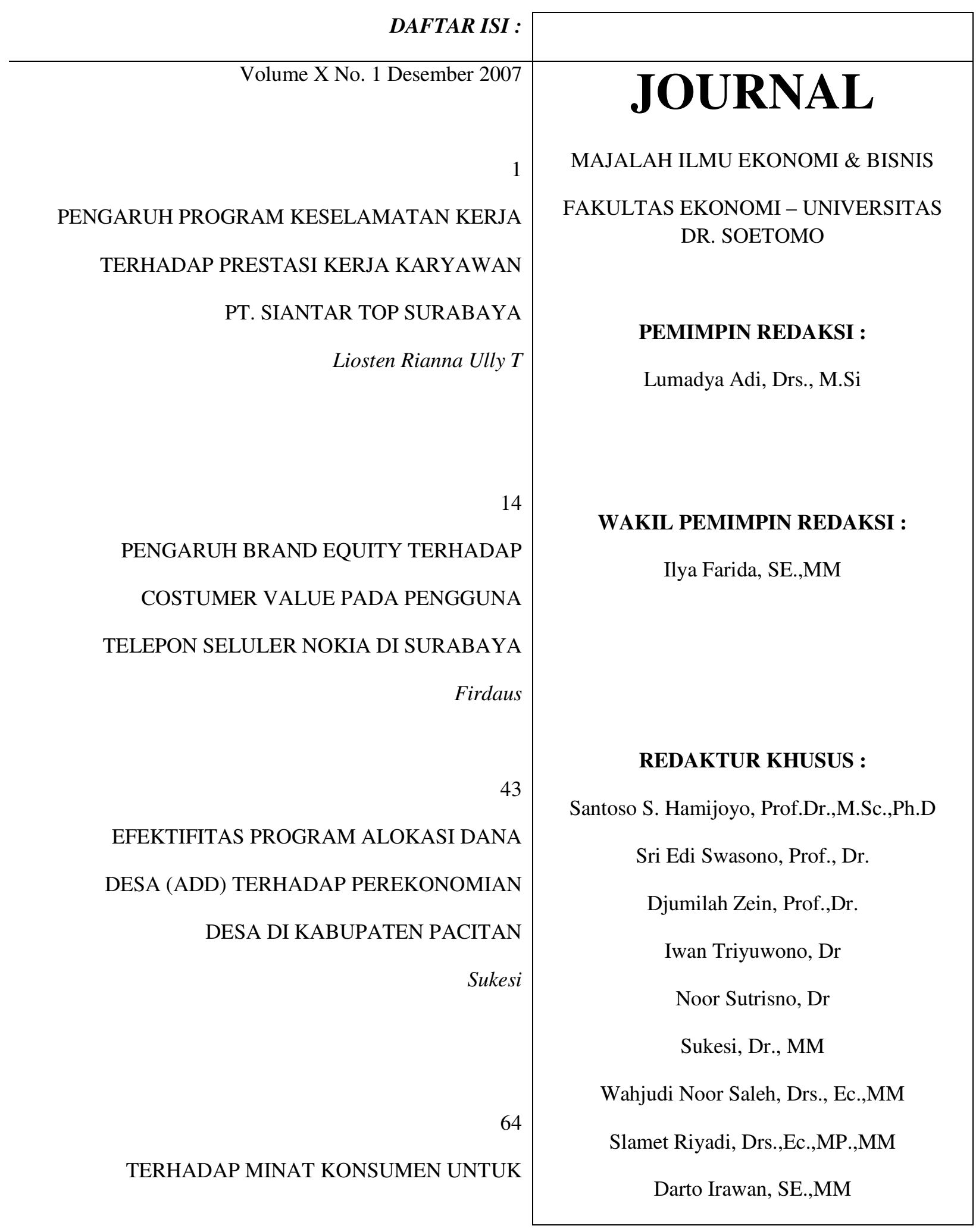


Veronica Nugraheni Sri Lestari

MEMBELI MOTOR HONDA SUPRA X 125

DI KAWASAN SURABAYA TIMUR

Mohammad Rusman

76

ANALISIS FAKTOR-FAKTOR PROMOSI DALAM

USAHA UNTUK MENINGKATKAN

VOLUME PENJUALAN

Veronika Nugraheni Sri Lestari

87

STUDI PERBANDINGAN LAJU INFLASI TUJUH

NEGARA INDUSTRI MAJU SEBELUM DENGAN

SESUDAH KENAIKAN HARGA MINYAK

Wiwik Budiarti

ANALISIS PENGARUH KUALITAS PELAYANAN

TERHADAP KEPUASAN ANGGOTA DI KOPERASI PEGAWAI REPUBLIK INDONESIA (KP-RI) BANGKIT KECAMATAN
Indrarini Utoro, Dra.Ec.,MM

Endang Susetyowati, Dra.,Ec.,MM

Djoko Sudiro, Drs., M.Si

Miftahol Horri, Drs. M.Si., Ak

\section{REDAKTUR :}

Rina Sulistyani, Dra., Ec

Muhammad Gozali Tafalas, SE., M.Si

Nur Sayidah, SE.,M.Si., Ak

\section{ALAMAT REDAKTUR :}

Fakultas Ekonomi Universitas Dr. Soetomo

Jl. Semolowaru 84 Surabaya

Telp. 031-5944752 Fax. 031-5964838

http : //ekonomi.unitomo.ac.id

email : ekonomi@unitomo.ac.id

journalfe@unitomo.ac.id

ISSN : 0854-4883 
Analisis Faktor-Faktor dalam Usaha untuk Meningkatkan Volume Penjualan

TRAGAH BANGKALAN

Manah Tarman 



\title{
ANALISIS FAKTOR-FAKTOP PROMOSI DALAM USAHA UNTUK MENINGKATKAN VOLUME PENJUALAN
}

\author{
Veronika Nugraheni Sri Lestari
}

Fakultas Ekonomi Universitas Dr. Soetomo

\begin{abstract}
ABSTRAKS
Setiap perusahaan mempunyai tujuan yang telah ditetapkan sebelumnya, baik yang bersifat jangka pendek maupun yang bersifat ;angka panjang. Pada dasarnya perusahaan menginginkan peningkatan volume penjualan, sehingga dapat memperoleh keuntungan atau laba yang diharapkan. Promosi perusahaan dalam usaha mengenalkan produknya kepada konsumen mempunyai peranan yang penting sebagai upaya untuk meningkatkan volume penjualan. Hal ini ditandai suatu pertimbangan bahwa suatu produk meskipun mempunyai arti yang penting bagi konsumen dan kualitas dapat diandalkan bila dibandingkan dengan produk perusahaan lain, tetapi jika tidak dikenalkan kepada konsumen melalui kegiatan promosi, maka produk tersebut tidak dikenal oleh konsumen, sehingga masyarakat tidak mengkonsumsinya.
\end{abstract}

Keywords : promosi, volume, penjualan, konsumen, produk

\subsection{Latar Belakang Masalah}

Dengan berkembangnya dunia industri yang semakin meningkat dan kemajuan teknologi yang sangat cepat, memungkinkan perusahaan akan mengalami persaingan yang semakin kuat. Kondisi semacam ini dapat mempengaruhi kelangsungan hidup perusahaan bila tidak bisa menyesuaikan dengan keadaan. 
Setiap perusahaan mempunyai tujuan yang telah ditetapkan sebelumnya, baik yang bersifat jangka pendek maupun yang bersifat jangka panjang. Pada dasarnya perusahaan menginginkan peningkatan volume penjualan, sehingga dapat memperoleh keuntungan atau laba yang diharapkan.

Sebagaimana kita ketahui bahwa pada dasarnya keberhasilan suatu organisasi dalam mencapai tujuannya serta menjaga kelangsungan hidup perusahaan tidak terlepas dari bidang pemasaran. Kegiatan pemasaran yang mempunyai peranan terhadap peningkatan volume penjualan adalah kegiatan promosi. Promosi dalam hal ini adalah sejenis kegiatan pemasaran yang ditujukan untuk memperkenalkan produk yang dihasilkan dan untuk mengimbangi persaingan pasar sejenis.

Promosi perusahaan dalam usaha mengenalkan produknya kepada konsumen mempunyai peranan yang penting sebagai upaya untuk meningkatkan volume penjualan. Hal ini dilandasi suatu pertimbangan bahwa suatu produk meskipun mempunyai arti yang penting bagi konsumen dan kualitas dapat diandalkan bila dibandingkan dengan produk perusahaan lain, tetapi jika tidak dikenalkan kepada konsumen melalui kegiatan promosi, maka produk tersebut tidak dikenal oleh konsumen, sehingga masyarakat tidak rnengkonsumsinya.

Sebagai obyek penelitian kami adalah PT. Sindotech Utama di Surabaya yang memproduksi cat waterproofing (cat pelapis anti bocor ) mengalami penurunan volume penjualan karena selama ini PT. Sindotech Utama masih belum mampu mencapai target penjualan seperti yang diharapkan oleh perusahaan. Oleh sebab itu perusahaan dapat meningkatkan volume penjualannya dengan melakukan kegiatan promosi, sehingga konsumen lebih mudah mengenal dan mendapatkan produk yang dihasilkan oleh perusahaan.

\subsection{Perumusan Masalah}

Berdasarkan latar belakang masalah diatas, maka perumusan masalah yang dapat diajukan adalah sebagai berikut : 
1. Apakah faktor - faktor promosi produk secara simultan mempunyai pengaruh yang signifikan terhadap volume penjualan, pada PT. Sindotech Utama Surabaya?

2. Faktor - faktor promosi manakah yang mempunyai pengaruh paling dominan terhadap volume penjualan pada PT. Sindotech Utama Surabaya?

\subsection{Tujuan Penelitian}

Adapun tujuan penelitian ini adalah :

1. Untuk menganalisa peranan promosi yang dilakukan oleh perusahaan terhadap volume penjualan pada PT. Sindotech Utama Surabaya.

2. Untuk menganalisa pengaruh promosi yang paving dominan terhadap volume penjualan pada PT. Sindotech Utama Surabaya.

\subsection{Manfaat Penelitian}

Adapun manfaat yang dapat diambil dari adanya penelitian ini antara lain :

1. Dari hasil penelitian ini diharapkan dapat digunakan sebagai masukan bagi perusahaan dalam pelaksanaan promosi dalam meningkatkan volume penjualan serta dapat membuat kebijakan atau pengambilan keputusan mengenai masalah promosi demi tercapainya tujuan perusahaan.

2. Hasil penelitian ini dapat digunakan untuk mengembangkan ilmu manajemen khususnya manajemen pemasaran sebagai dasar penelitian selanjutnya.

\section{TINJAUAN PUSTAKA DAN HIPOTESIS}




\subsection{Pengertian Pemasaran}

Pemasaran menurut Malcolm dan Warren J. Keegan (1999:1) adalah: Semua aktivitas untuk memperlancar arus barang atau jasa dari produsen ke konsumen secara efisien dengan maksud untuk menciptakan permintaan yang efektif.

Selanjutnya Philip Kotler dan Gary Armstrong (1996 : 6) mengemukakan sebagai berikut : Suatu proses sosial dare manajerial yang membuat individu dan kelompok memperoleh apa yang mereka butuhkan serta inginkan lewat penciptaan dan pertukaran timbal balik produk dan nilai dengan prang lain.

\subsection{Pengertian Promosi}

Menurut Basu Swastha 0996 : 234) adalah : Kegiatan komunikasi yang dilakukan pembeli dan penjual dan merupakan kegiatan yang membantu dalam pengambilan keputusan di bidang pemasaran serta mengarahkan pertukaran agar lebih memuaskan dengan cara menyadarkan semua produk untuk berbuat lebih baik.

Pengertian lain menurut Fandy Tjiptono (1996 : 219) : Promosi adalah suatu bentuk aktivitas pemasaran yang menjabarkan informasi, mempengaruhi/membujuk, atau meningkatkan pasar sasaran atas perusahaan dan produknya agar bersedia menerima, membeli dan loyal kepada produk yang ditawarkan perusahaan yang bersangkutan.

\subsection{Pengertian Personal Selling}

Salah satu metode untuk mencapai tujuan tersebut adalah personal selling menurut Winardi (1995: 113) yaitu : Interaksi antar pribadi dan secara tatap muka untuk mencapai tujuan menciptakan, memodifikasi, mengeksploitasi atau mengusahakan timbulnya suatu hubungan pertukaran yang saling menguntungkan dengan pihak lain”.

\subsection{Advertising (Periklanan)}


Keberhasilan pemasaran suatu produk atau jasa harus didukung dengan adanya program komunikasi yang efektif ditujukan kepada konsumen. Salah satu bentuk komunikasi tersebut adalah dengan melaksanakan periklanan atau periklanan. Pengertian periklanan menurut Philip Kotler (1997 : 269) adalah :

Merupakan salah satu dari empat alat utama yang digunakan oleh perusahaan untuk mengarahkan komunikasi yang meyakinkan kepada pembeli dan publik sasaran, bentuk-bentuk komunikasi non pribadi (non personal) yang diselenggarakan melalui media yang dibayar dengan sponsor yang nyata atau jelas.

Suhardi Sigit (1998 : 50) memberikan pengertian periklanan bahwa : "Cara penyajian dengan catatan, tulisan, kata-kata, gambar atau menggunakan orang, produk atau jasa, yang dilakukan oleh suatu lembaga (perusahaan) dengan tujuan untuk mempengaruhi dan meningkatkan pemakaian atau memperoleh suara, dukungan atau pendapat".

Menurut Fandy Tjiptono (1996 : 226) bahwa : "Iklan adalah bentuk komunikasi tidak langsung, yang didasari pada informasi tentang keunggulan atau keuntungan suatu produk, yang disusun sedemikian rupa sehingga menimbulkan rasa menyenangkan yang akan mengubah pikiran seseorang untuk melakukan pembelian”.

\subsection{Faktor-faktor yang Mempengaruhi Volume Penuuulan}

Produsen harus memperhatikan berbagai macam faktor yang sangat mempengaruhi dalam volume penjualan seperti yang dikatakan oleh Alex S. Nitisemilo $(1997 ; 209)$ antara lain menyangkut :

Faktor intern

a. Kualitas produksi

b. Service yang diberikan

c. Sering kosongnya barang di pasaran 
d. Penurunan kegiatan sales promotion

e. Adanya penetapan harga

Faktor extern

a. Perubahan selera konsumen

b. Munculnya saingan baru

c. Munculnya barang pengganti

d. Pengaruh faktor psychologi

e. Perubahan baru dalam kebijaksanaan pemerintah

f. Kemungkinan adanya tindakan dari pesaing.

\subsection{Kaitan Antara Penjualan Dengan Promosi}

Telah dijelaskan maka bahwa hubungan promosi merupakan salah satu cara untuk melakukan suatu tindakan komunikasi kepada pembeli agar perusahaan dapat meningkatkan volume penjualan dimana dengan meningkatnya volume penjualan tersebut perusahaan dan mendapatkan keuntungan yang diperoleh semakin meningkat, sehingga dari hasil keuntungan yang diperoleh perusahaan digunakan untuk biaya operasionalnya serta untuk menambah dana atau biaya promosi yang lebih besar lagi.

Pengertian dan batasan mengenai promosi, dikatakan bahwa promosi adalah suatu bentuk aktivitas pemasaran yang menjabarkan informasi, mempengaruhi/ membujuk, atau meningkatkan pasar sasaran atas perusahaan dan produknya agar bersedia menerima, membeli dan loyal kepada produk yang ditawarkan perusahaan yang bersangkutan.

Dengan adanya promosi, konsumen tidak hanya sekedar tahu akan hasil produk namun secara langsung dapat mengenalkan keunggulan produk balk barang ataupun 
kualitas yang dihasilkan oleh perusahaan. Promosi itu sendiri menitik beratkan pada usaha untuk menciptakan kesadaran pada konsumen tentang sebuah barang dan kualitas daripada barang itu sendiri.

\section{Hipotesis}

Berdasarkan latar belakang masalah yang telah dikemukakan di atas dan permasalahan yang dihadapi oleh perusahaan, maka dapat dirumuskan suatu hipotesa sebagai berikut :

1. Diduga variabel sales promotion, personal selling dan advertising secara simultan mempunyai pengaruh yang signifikan terhadap volume penjualan pada PT. Sindotech Utama Surabaya.

2. Diduga dari salah satu vas label bebas tersebut yaitu salespromotion berpengaruh paling dominan terhadap volume penjualan PT. Sindotech Utama Surabaya.

\section{Metodologi Penelitian}

\subsection{Identifikasi Variabel Penelitian}

a. Promosi sebagai variabel bebas (X), terdiri dari

1. Sales promotion adalah selaku variabel $\left(\mathrm{X}_{1}\right)$

2. Personal selling (variabel $\mathrm{X}_{2}$ )

3. Advertising $\left(\mathrm{X}_{3}\right)$

b. Volume penjualan (Y) sebagai variabel terikat 


\subsection{Jenis dan Sumber Data}

Jenis dan Sumber data dalam penelitian ini adalah : jenis data seluruhnya adalah data sekunder dari perusahaan . Data yang digunakan merupakan data dari tahun 1996 s/d 2003.

\subsection{Model Teknik Analisis}

Dalam melakukan analisis terhadap data-data yang ada digunakan model Analisa regresi linear berganda, untuk mengetahui hubungan pengaruh variabel bebas (x) terhadap variabel terikat $(\mathrm{y})$, digunakan rumus :

1. $Y=a+b_{1} \cdot X_{1}+b_{2} \cdot X_{2}+b_{3} \cdot X_{3}$

\section{Dimana :}

$$
\begin{array}{ll}
\mathrm{a} & =\text { Konstanta } \\
\mathrm{b}_{1} \mathrm{~b}_{2} \mathrm{~b}_{3} & =\text { Koefisien regresi } \\
\mathrm{X}_{1} & =\text { Sales promotion } \\
\mathrm{X}_{2} & =\text { Personal selling } \\
\mathrm{X}_{3} & =\text { Advertising } \\
\mathrm{Y} & =\text { Volume penjualan }
\end{array}
$$

\subsection{Teknik Analisis}

a. Uji-F Analisa ini menurut bertujuan untuk membuktikan apakah hipotesa yang telah dirumuskan diterima atau ditolak. 
Adapun rumus yang digunakan adalah :

$$
F \frac{R^{2} / K}{\left(1-R^{2}\right) /(n-\bar{k}-1)}
$$

Dimana :

$$
\mathrm{R}^{2}=\text { koefisien korelasi }
$$

$\mathrm{n} \quad=$ banyaknya data

$\mathrm{k} \quad=$ banyaknya variabel bebas

$\mathrm{F} \quad=\mathrm{F}$ hitung yang selanjutnya dibandingkan dengan $\mathrm{F}$ tabel

b. Uji t (t-test)

Digunakan untuk menguji signifikan pengaruh perbagian dari masing-masing variabel bebas terhadap variabel terikat.

Rumus :

$t$ hitung $\frac{\beta i}{S \beta i}$

Keterangan :

$\beta \mathrm{i}=$ koefisien regresi

$S \beta \mathrm{i}=$ Standar deviasi

\section{HASIL PENELITIAN DAN PEMBAHASAN}

\subsection{Regresi Linear Berganda}

Berdasarkan hasil perhitungan regresi linear berganda tersebut maka dapat disusun persamaan regresi linear berganda sebagai berikut : 


$$
Y=43611,604+1,218 X_{1}+3,474 X_{2}+1,209 X_{3}
$$

Dari persamaan diatas dapat diinterpretasikan sebagai berikut :

1. $\mathrm{a}=43611,604$ mengandung pengertian bahwa perpotongan garis regresi pada sumbu variabel (Y) terletak pada 43611,604 Nilai konstanta $=43611,604$ juga berarti bahwa meskipun sales promotion, personal selling dan advertising tidak dilaksanakan maka volume penjualan perusahaan sebesar 43611,604

2. $b_{1}=1,218$ nilai ini mengandung pengertian bahwa $X$, (sales promotion) berpengaruh positif terhadap volume penjualan (Y) apabila X, (sales promotion) naik sebesar satu satuan, maka akan diikuti kenaikan volume penjualan sebesar 1,218 dengan asumsi bahwa variabel personal selling dan advertising konstan.

3. $b_{2}=3,474$ nilai ini mengandung pengertian bahwa variabel personal selling berpengaruh positif searah terhadap volume penjualan apabila $\mathrm{X}_{2}$ (personal selling) naik sebesar satu satuan, maka akan diikuti kenaikan volume penjualan sebesar 3,474 dengan asumsi bahwa variabel sales promotion dan advertising konstan.

4. $b_{3}=1,209$ nilai ini mengandung pengertian bahwa variabel advertising berpengaruh positif searah terhadap volume penjualan, apabila $\mathrm{X}_{3}$ (advertising) naik sebesar satu satuan, maka akan diikuti kenaikan volume penjualan sebesar 1,209 dengan asumsi bahwa variabel salespromotion dan personal selling konstan.

\subsection{Koefisien Determinasi}

Berdasarkan hasil pengolahan data didapatkan koefisien korelasi (R) sebesar 0,908. Nilai ini dapat diartikan bahwa terdapat hubungan antara sales promotion, personal selling dan advertising dengan volume penjualan.

Sedangkan pengolahan data juga diperoleh nilai dari koefisien determinasi $\left(\mathrm{R}^{2}\right)$ yaitu sebesar 0,825 artinya variasi (naik turunnya) volume penjualan (Y) mampu 
diterangkan oleh perubahan variabel salespromotion $\left(\mathrm{X}_{1}\right)$, personal selling $\left(\mathrm{X}_{2}\right)$ dan advertising $\left(\mathrm{X}_{3}\right)$ sebesar $825 \%$. Sementara itu sisanya yaitu sebesar $17,5 \%$ dipengaruhi oleh variabel lain diluar persamaan yang telah ditentukan.

\subsection{Uji F}

Dari hasil pengujian data dilihat bahwa besarnya F hitung adalah 14,962 dengan signifikan 0,002. Sedangkan besarnya $\mathrm{F}$ tabel $=3,49$. Dengan demikian dapat diperoleh bahwa $\mathrm{F}$ hitung $=14,962>\mathrm{F}$ tabel $=3,49$. Berdasarkan kriteria pengujian uji $\mathrm{F}$ maka dapat disimpulkan bahwa $\mathrm{H}$; diterima dan $\mathrm{H}$, ditolak dengan kata lain bahwa hipotesis yang menyatakan bahwa salespromotion, personal selling dan advertising secara bersama-sama berpengaruh terhadap volume penjualan terbukti secara signifikan dan dapat diterima.

\subsection{Uji t}

Dari hasil pengujian dapat dilihat bahwa nilai t hitung variabel salespromotion $\left(\mathrm{X}_{1}\right)$ adalah sebesar 5,360 dengan signifikansi pengujian sebesar 0,000. Dengan demikian sesuai dengan kriteria pengujian uji t maka dapat disimpulkan bahwa thitung $=5,360>\mathrm{t}$ tabel $=2,179$. Dengan demikian $\mathrm{H}_{\mathrm{o}}$ ditolak dan $\mathrm{H}_{\mathrm{i}}$ diterima. Dengan kata lain dapat dinyatakan bahwa salespromotion berpengaruh signifikan terhadap volume penjualan.

Dari data (coefficients) dapat dilihat bahwa nilai t hitung variabel personal selling $\left(\mathrm{X}_{2}\right)$ adalah sebesar 3,362 dengar signifikansi pengujian sebesar 0,001. Dengan demikian sesuai dengan kriteria pengujian Uji t maka dapat disimpulkan bahwa t hitung $=3,362>\mathrm{t}$ tabel $=2,179$. Dengan demikian $\mathrm{H}_{\mathrm{o}}$ ditolak dan $\mathrm{H}_{\mathrm{i}}$ diterima. Dengan kata lain dapat dinyatakan bahwa personal selling berpengaruh signifikan terhadap volume penjualan.

Dari data (coefficients) dapat dilihat bahwa nilai t hitung variabel advertising $\left(\mathrm{X}_{3}\right)$ 
adalah sebesar 3,788 dengan signifikan pengujian sebesar 0,000. Dengan demikian sesuai dengan kriteria pengujian uji t maka dapat disimpulkan bahwa thitung = 3,788 > $\mathrm{t}$ tabel $=2,179$. Dengan demikian $\mathrm{H}_{\mathrm{o}}$ ditolak dan $\mathrm{H}_{\mathrm{i}}$ diterima. Dengan kata lain dapat dinyatakan bahwa variabel advertising berpengaruh signifikan terhadap volume penjualan.

Berdasarkan pengujian uji t tersebut maka dapat disimpulkan bahwa variabel salespromotion, personal selling dan advertising berpengaruh signifikan terhadap volume penjualan. 


\subsection{Uji $\mathbf{r}^{2}$ Parsial}

Untuk mengetahui variabel yang paling kuat b:rpengaruh pada volume penjualan pada PT. Sindotech Utama Surabaya, maka digunakan $r^{2}$ parsial. Yaitu $r^{2}$ tertingi menunjukkan variabel bebas yang paling kuat berpengaruh terhadap variabel terikat.

Tabel 1

\section{Rekapitulasi Pengaruh Secara Parsial}

\begin{tabular}{|c|c|c|}
\hline Variabel & $\mathrm{r}^{2}$ Parsial & Probabilitas \\
\hline $\mathrm{X}_{1}$ & 0,300 & 0,000 \\
$\mathrm{X}_{2}$ & 0,759 & 0,001 \\
$\mathrm{X}_{3}$ & 0,200 & 0,000 \\
\hline
\end{tabular}

Dari tabel tersebut, hasil uji parsial menunjukkan bahwa variabel personal selling mempunyai pengaruh yang paling besar yaitu 75,9 \%, berarti variabel personal selling dinyatakan sebagai variabel yang paling dominan terhadap volume penjualan pada PT. Sindotech Utama Surabaya.

Berdasarkan analisis di atas maka dapat diuraikan bahwa salespromotion, personal selling dan advertising mempunyai pengaruh yang signifikan terhadap volume penjualan. Dari hasil perhitungan juga diperoleh nilai koefisien determinasi $\left(\mathrm{R}^{2}\right)$ yaitu sebesar 0,825. Artinya variasi (naik turunnya) volume penjualan (Y) mampu diterangkan oleh perubahan variabel sales promotion $\left(\mathrm{X}_{1}\right)$, personalselling $\left(\mathrm{X}_{2}\right)$, dan advertising $\left(\mathrm{X}_{3}\right)$ sebesar $82,5 \%$. Sementara itu sisanya yaitu sebesar $17,5 \%$ dipengaruhi oleh variabel lain diluar persamaan yang telah ditentukan.

Berdasarkan keadaan di atas maka peneliti mencoba mengemukakan pemecahan masalah sebagai bahan pertimbangan untuk pengambilan keputusan yang lebih lanjut sebagai berikut : 
a. Kurang efektifnya penggunaan alat-alat promosi maka akan mengakibatkan sasaran yang akan dituju dalam kaitannya dengan tujuan promosi ini dilakukan tidak tercapai. Hal ini akan mengakibatkan penjualan akan menurun sehingga volume penjualan yang ditargetkan tidak tercapai. Perusahaan perlu meningkatkan frekuensi promosi penjualan melalui kegiatan pameran-pameran di daerah-daerah maupun luar daerah. Dalam pameran-pameran ini akan lebih merangsang lagi apabila harga di discount sekian persen. Dengan adanya promosi penjualan

1. Merangsang konsumen untuk membeli produk, karena ada potongan harga.

2. Konsumen diharapkan pada pemilihan alternatif harga yang lebih murah. Sehingga akan menarik minat konsumen untuk membeli.

b. Pihak manajemen harus lebih banyak memperhatikan personal selling, dimana besarnya dana yang dialokasikan ke personal selling selama ini nilainya di bawah sales promotion. Sedangkan dari analisis data yang dilakukan oleh penulis mendapatkan variabel personal selling merupakan variabel yang paling dominan dibandingkan dengan variabel salespromotion dan variabeladvertising. Sehingga personal selling harus mendapatkan prioritas yang pertama dalam hal besar dan pengalokasian dana. Dan pada akhirnya diharapkan para konsumen atau calon konsumen akar terpengaruh lain tertarik untuk membeli produk yang diiklankan tersebut. Sehingga volume penjualan akan meningkat seperti yang diharapkan.

Dengan pemecahan masalah tersebut diatas, maka diharapkan perusahaan dapat menjadikan hal tersebut sebagai bahan pertimbangan dalam mengambil keputusan sehingga target penjualan yang direncanakan dapat tercapai.

\subsection{Simpulan}

Berdasarkan pada uraian, analisis dan pembahasan tentang faktor- faktor promosi yang mempengaruhi volume penjualan pada PT. Sindotech Utama Surabaya maka dapat dibuat kesimpulan sebagai berikut : 
1. Bahwa variabel independen yaitu sales promotion, personal selling dan advertising sangat berpengaruh terhadap volume penjualan ini dapat kita lihat pada pembahasan yaitu :

a. Variabel sales promotion $\left(\mathrm{X}_{1}\right)$

Dimana variabel ini memiliki hubungan positif dan signifikan dengan penjualan. Hal ini ditunjukkan oleh nilai t hitung $>\mathrm{t}$ tabel atau 5,360 $>2,179$. Nilai koefisien regresi sebesar 1,218 mengandung pengertian bahwa sales promotion $\left(\mathrm{X}_{1}\right)$ naik sebesar satu rupiah maka akan diiringi dengan kenaikan volume penjualan sebesar 1,218 dengan asumsi bahwa variabel personal selling dan advertising konstan.

b. Variabel personal selling $\left(\mathrm{X}_{2}\right)$

Dimana variabel ini memiliki hubungan positif dan signifikan dengan penjualan. Hal ini ditunjukkan oleh nilai t hitung $>\mathrm{t}$ tabel atau 3,362 $>2,179$. Nilai koefisien regresi sebesar 3,474 mengandung pengertian bahwa sales promotion $\left(\mathrm{X}_{1}\right)$ naik sebesar satu rupiah maka akan diiringi dengan kenaikan volume penjualan sebesar 3,474 dengan asumsi bahwa variabel sales promotion dan advertising konstan.

c. Variabel advertising $\left(\mathrm{X}_{3}\right)$

Dimana variabel ini memiliki hubungan positif dan signifikan dengan penjualan. Hal ini ditunjukkan oleh nilai $t$ hitung $>t$ tabel atau 3,788 $>2,179$. Nilai koefisien regresi sebesar 1,209 mengandung pengertian bahwa sales promotion $\left(\mathrm{X}_{1}\right)$ naik sebesar satu rupiah maka akan diiringi dengan kenaikan volume penjualan sebesar 1,209 dengan asumsi bahwa variabel sales promotion dan personal selling konstan.

2. Berdasarkan analisis uji $F$ dapat diketahui bahwa besarnya $F$ hitung adalah 14,962 sedangkan F tabel adalah sebesar 3,49. Dengan demikian terlihat bahwa F hitung $>\mathrm{F}$ tabel sehingga Hi diterima dan Ho ditolak. Dengan kata lain bahwa hipotesis yang menyatakan bahwa secara simultan atau secara bersama-sama variabel sales promotion, personal selling dan advertising berpengaruh terhadap volume penjualan 
terbukti nyata dan dapat diterima.

3. Berdasarkan pembahasan menunjukkan bahwa variabel personal selling mempunyai pengaruh yang paling besar yaitu 75,9 \%, dengan kata lain personal selling merupakan variabel yang paling dominan terhadap volume penjualan pada PT. Sindotech Utama Surabaya.

\subsection{Saran}

Berdasarkan simpulan yang ditarik dari uraian dan pembahasan diatas, maka peneliti memberikan saran-saran yang mungkin bermanfaat untuk meningkatkan volume penjualan khususnya pada PT. Sindotech Utama Surabaya yaitu :

a. Pihak manajemen harus lebih banyak memperhatikan personal selling, dimana besarnya dana yang dialokasikan ke personal selling selama ini nilainya di bawah sales promotion. Sedangkan dari analisis data yang dilakukan oleh penulis mendapatkan variabel personal selling merupakan variabel yang paling dominan dibandingkan dengan variabel sales promotion dan variabel advertising. Sehingga personal selling harus mendapatkan prioritas yang pertama dalam hal besar dan pengalokasian dana. Dan pada akhirnya diharapkan para konsumen atau calon konsumen akan terpengaruh lalu tertarik untuk membeli produk yang diiklankan, tersebut. Sehingga volume penjualan akan meningkat seperti yang diharapkan.

\section{DAFTAR PUSTAKA}

Alex S. Nitisemito, Wawasan Manajemen, Grafiti, Jakarta, 1997

Basu Swastha DH, Asas-asas marketing, Edisi Ketiga, Liberty, Yogyakarta, 1995 Basu Swastha, Manajemen Pemasaran Modern, Liberty, Yogyakarta, 1995 
Fandy Tjiptono, Strategi Pemasaran, Edisi II, Penerbit ANDI, Yogyakarta, 1996

Malcolm dan Warren J. Keegen, Marketing Plans, Gramedia, Jakarta, 1999

Philip Kotler dan Gary Armstrong, Dasar-dasar Pemasaran, Edisi Bahasa Indonesia, Jilid I, Prenhallindo, Jakarta.

Radiosunu, Politik Pemasaran, Penerbit Ghalia Indonesia, Jakarta, 1996

Rhenald Kasali, Manajemen Periklanan, Grafiti, Jakarta, 1992

Rhenald Kasali, Membidik Pasar Indonesia, Gramedia, 1996

Suhardi Sigit, Manajemen Pemasaran, Penerbit ghalia Indonesia, Jakarta, 1996

Torn Brannon, A Practical guide To Integrated Marketing Communications, Gramedia Jakarta, 1998

Winardi, Manajemen pemasaran, Cetakan Pertama, Penerbit CV. Sinar baru, Bandung 1995

Winarno Surachmad, Pengantar Metodologi Penelitian, Edisi Keenam, Cetakan, Kedelapan, Penerbit Tarsito Bandung, 1995 